Experience of maternal and paternal adversities in childhood as determinants of self-harm in adolescence and young adulthood

\title{
Pitkänen, Joonas
}

$2019-11$

Pitkänen , J , Remes , H , Aaltonen , M \& Martikainen , P 2019 , ' Experience of maternal and paternal adversities in childhood as determinants of self-harm in adolescence and young adulthood ', Journal of Epidemiology \& Community Health , vol. 73 , no. 11, pp. pÿ1040 1046 . https://doi.org/10.1136/jech-2019-212689

http://hdl.handle.net/10138/311665

https://doi.org/10.1136/jech-2019-212689

acceptedVersion

Downloaded from Helda, University of Helsinki institutional repository.

This is an electronic reprint of the original article.

This reprint may differ from the original in pagination and typographic detail.

Please cite the original version. 
This article has been accepted for publication in Journal of Epidemiology and Community Health 2019 following peer review, and the Version of Record can be accessed online at http://dx.doi.org/10.1136/jech-2019-212689.

(C) Authors

Experience of maternal and paternal adversities in childhood as determinants of self-harm in adolescence and young adulthood

Joonas Pitkänen, Population Research Unit, Faculty of Social Sciences, University of Helsinki, Helsinki, Finland.

Hanna Remes, Population Research Unit, Faculty of Social Sciences, University of Helsinki, Helsinki, Finland.

Mikko Aaltonen, Institute of Criminology and Legal Policy, Faculty of Social Sciences, University of Helsinki, Helsinki, Finland.

Pekka Martikainen, Population Research Unit, Faculty of Social Sciences, University of Helsinki, Helsinki, Finland; Centre for Health Equity Studies (CHESS), Stockholm University and Karolinska Institutet, Stockholm, Sweden; Max Planck Institute for Demographic Research, Rostock, Germany

Corresponding author:

Joonas Pitkänen, Population Research Unit, Faculty of Social Sciences, University of Helsinki, Helsinki, Finland

P.O. Box 18, FIN-00014 University of Helsinki, Finland joonas.pitkanen@helsinki.fi 


\begin{abstract}
Introduction

Previous studies suggest that childhood experience of parental adversities increase the risk of subsequent offspring self-harm, but studies on distinct paternal and maternal characteristics are few and it remains unclear how these interact with childhood social position. The study aims to assess whether paternal and maternal adversities have different associations with offspring self-harm in adolescence and young adulthood. Interaction by offspring gender and childhood income are investigated, as well as cumulative effects of multiple adversities.
\end{abstract}

\title{
Methods
}

The study uses administrative register data on a 20\% random sample of Finnish households with 014-year-old children in 2000. We follow children born in 1986-1998 $(\mathrm{N}=155,855)$ from their 13 th birthday until 2011. Parental substance abuse, psychiatric disorders, criminality and hospitalizations due to interpersonal violence or self-harm are used to predict offspring self-harm with Cox proportional hazards models.

\section{Results}

The results show a clear increase in the risk of self-harm among those exposed to maternal or paternal adversities with hazard ratios between 1.5 and 5.4 among boys and 1.7 and 3.9 among girls. The excess risks hold for every measure of maternal and paternal adversity after adjusting for childhood income and parental education. Evidence was found suggesting that low-income, accumulation of adversity and female gender may exacerbate the consequences of adversities.

\section{Conclusions}

Our findings suggest that both parents' adversities increase the risk of self-harm and that multiple experiences of parental adversities in childhood are especially harmful, regardless of parent gender. 
Higher levels of childhood income can protect from the negative consequences of adverse experiences.

Keywords: childhood adversity; maternal and paternal adversity; self-harm; adolescence; young adulthood; gender differences; socioeconomic resources 


\section{RESEARCH REPORT BOX}

\section{What is already known on this subject?}

There is a well-established link between parental adversities, such as parental substance abuse or psychiatric disorders, and elevated risk of offspring self-harm in adolescence and young adulthood. However, previous work has usually combined information on both parents, and it remains unclear whether maternal and paternal adversity are differently associated with offspring self-harm. Furthermore, as economic disadvantage is often considered as an independent measure of adversity, the evidence on interaction effects between parental adversities and social position is scarce.

\section{What does this study add?}

This study contributes to previous literature by showing that maternal and paternal adversities increase the risk of self-harm in adolescence and young adulthood, regardless of parent or offspring gender. Moreover, results from this study indicate that maternal and paternal adversities reinforce each other and that adversities have more severe consequences in low-income households. The latter implies that supportive policy measures for low-income groups could effectively protect from the negative consequences of parental adversity in these families. 


\section{INTRODUCTION}

Self-harming behaviors form a continuum ranging from non-lethal injuries and poisonings to suicides [1-3]. In high-income countries, self-harm is quite common among adolescents, with a community-level mean lifetime prevalence estimates of non-fatal self-harm around $18 \%$ [4,5], and suicide is the leading cause of death in 15-29-year-olds in the member states of the European Union [6]. Non-lethal self-harm is more common among females, whereas males have a larger share in suicides $[1,2]$.

Previous research has repeatedly shown that a diverse range of childhood adversities is associated with self-harm in adolescence. Those with childhood experience of parental psychiatric disorders, substance abuse, parental separation, and child welfare interventions have been shown to have increased risk of non-fatal [7-11] and fatal self-harm [12-14]. Childhood economic adversity and low socioeconomic position have also been linked with increased risk of self-harm [15-19]. In addition, adverse experiences are more common in economically disadvantaged households and the combination of low socioeconomic position and other adversity can be especially harmful for children $[20,21]$. A recent review also suggests that these life-course determinants of self-harm may have gender differences [22].

The mechanisms through which childhood adversities increase the risk of self-harm are manifold. Adverse experiences in childhood may have consequences for child development, which increases the risk of behavioural and emotional problems [10,23,24]. Parental adversities, such as severe psychiatric disorders and substance abuse, are likely to hamper parenting capabilities [20] and increase the risk of maltreatment [25]. Furthermore, mental health problems and health-risk behaviors are transmitted across generations through genes and parental modelling [20,26]. Impairment of parenting behaviors due to health or social problems may have different consequences for child well-being depending on parent's gender [27-29], due to gendered household roles [30] as well as differences in parent-child relationships [29]. For instance, mothers are often the primary attachment-figure [31] and mother-child relationships more characterized by 
warmth and nurture than father-child relationships [29]. However, little is known whether maternal and paternal characteristics impact differently on offspring self-harm. In terms of suicide risk, there is evidence that loss of mother could be more detrimental than loss of father [14] but to our knowledge, no studies comparing maternal and paternal adversities and their associations with hospital-presenting self-harm have been conducted. Moreover, we have no prior evidence as to whether these adversities have similar effects across the social gradient.

In this study, we assess whether childhood experiences of paternal and maternal adversity differ from each other in terms of increased risk of self-harm in adolescence and young adulthood, and if these associations are different by offspring gender. In addition, we test whether low childhood income aggravates the negative consequences of parental adversities and if the association between multiple adversities and self-harm is cumulative.

\section{METHODS}

\section{Data}

We use administrative register data on a 20\% sample of Finnish households with 0-14-year-old children in 2000. The sample includes all the individuals in these households and the non-coresident biological parents of all the children. The data consist of sociodemographic information, hospital discharge records, information on purchases of prescription medication and all suspected criminal offences known to the police (see Table 1 for details). The anonymized data has been approved for use in research by the Board of Statistical Ethics of Statistics Finland (TK-53-525-11).

Our analyses are limited to children born in Finland in 1986-1998 (n=159,497). We exclude the children with missing data on their biological parents $(n=2,281)$, those hospitalized due to self-harm prior to age $13(n=22)$ and those who died $(n=72)$ or emigrated $(n=1,267)$ prior to the start of the follow-up. The final size of the analytical sample is 155,855 individuals and 1,016,147 personyears. Loss to follow-up due to deaths (other than suicides) and emigration was 3,485 person-years $(n=1,034)$. 


\section{Study outcome}

Using the Finnish Hospital Discharge Register that covers all institutions providing hospital-level care, we define self-harm as being hospitalized due to intentional self-harm. All episodes with external causes of morbidity referring to intentional self-harm (International classification of diseases (ICD10): X60-X84 and Y870) are included in the outcome, regardless of the means of self-harm. Furthermore, because some hospital episodes are fatal and characterized by suicidal intent [1], we supplement the outcome with suicides, determined from Statistics Finland's data on causes of death and using the same ICD10 codes as above.

We performed a sensitivity analysis in which suicides were excluded and the results were almost identical (Supplementary Figures 1 and 2). Due to small number of events, using only suicides as an outcome produced inconsistent results.

\section{Maternal and paternal adversities}

We use maternal and paternal substance abuse, psychiatric disorders, criminality and hospitalizations due to interpersonal violence or self-harm as measures of adversity and define these from hospital discharge records, prescription medication purchases and offences known to police. The adversities identified from hospitalizations are measured from the age of 0 to 12 (for cohort 1986, 1-12), with exposure at any point in time contributing to measurement. Due to data availability issues parental criminality and purchases of prescription medication have different measurement periods by cohort. All the variables are described in detail in Table 1 . 


\begin{tabular}{|c|c|c|c|}
\hline Variable & Definition & Measurement time & Source \\
\hline Self-harm & ICD10: X60-X84; Y870 & $\begin{array}{l}\text { From } 13^{\text {th }} \text { birthday } \\
\text { onwards, until the } \\
\text { end of } 2011 \text { (Ages } \\
13-25)\end{array}$ & $\begin{array}{l}\text { Hospital discharge } \\
\text { records (1987-2011), } \\
\text { National Institute for } \\
\text { Health and Welfare; } \\
\text { Causes of death } \\
\text { (1987-2011), } \\
\text { Statistics Finland }\end{array}$ \\
\hline $\begin{array}{l}\text { Parental } \\
\text { substance abuse } \\
\text { (hospitalizations) }\end{array}$ & $\begin{array}{l}\text { ICD9: 291; 292; 303; 3040-3045; 3049; 3050; } \\
\text { 3052-3059;2650A; 3575; 4255 5353 5710; 5712; } \\
\text { 5713; 5770D; 5770E; 5770F; 5771C 5771D; } \\
\text { 969; 9701; 5307 } \\
\text { ICD10: F10-F16; F18-F19; E244; E52; G312; } \\
\text { G4051; G621; G721; I426 K292; K852; K860; } \\
\text { R780 T51; Y901 Z502; Z714 Z721; B171; R781- } \\
\text { R785; T36; T40; T423; T424; T426; T427; } \\
\text { T430-T436 T438; T439; T507; Z503; Z715; } \\
\text { Z722 }\end{array}$ & Child's age $0-12$ & $\begin{array}{l}\text { Hospital discharge } \\
\text { records (1987-2011), } \\
\text { National Institute for } \\
\text { Health and Welfare }\end{array}$ \\
\hline $\begin{array}{l}\text { Parental } \\
\text { substance abuse } \\
\text { (crime) }\end{array}$ & $\begin{array}{l}\text { Any drug or alcohol-related offence known to } \\
\text { police, including driving under influence. }\end{array}$ & $\begin{array}{l}\text { Child's age: } \\
\text { Cohort 1986:10-12 } \\
\text { Cohort 1987: 9-12 } \\
\text { ‥ } \\
\text { Cohort 1998: 0-12 }\end{array}$ & $\begin{array}{l}\text { Offences known to } \\
\text { police (1996-2012), } \\
\text { Statistics Finland }\end{array}$ \\
\hline $\begin{array}{l}\text { Parental } \\
\text { psychiatric } \\
\text { disorder } \\
\text { (hospitalizations) }\end{array}$ & $\begin{array}{l}\text { ICD9: 295-298; 300-302; 307; 309; 310; 312; } \\
316 \\
\text { ICD10: F20-F29; F30-F39; F40-F48; F50-F59; } \\
\text { F60-F69; F99 }\end{array}$ & Child's age $0-12$ & $\begin{array}{l}\text { Hospital discharge } \\
\text { records (1987-2011), } \\
\text { National Institute for } \\
\text { Health and Welfare }\end{array}$ \\
\hline $\begin{array}{l}\text { Parental } \\
\text { psychiatric } \\
\text { disorder } \\
\text { (medication } \\
\text { purchases) }\end{array}$ & ATC: N05; N06A-N06C; N07A; N07C N07X & $\begin{array}{l}\text { Child's age: } \\
\text { Cohort 1986:9-12 } \\
\text { Cohort 1987: 8-12 } \\
\text { ‥ } \\
\text { Cohort 1998: 0-12 }\end{array}$ & $\begin{array}{l}\text { Purchases of } \\
\text { prescription } \\
\text { medication (1995- } \\
\text { 2012), Social } \\
\text { Insurance Institution } \\
\text { of Finland }\end{array}$ \\
\hline $\begin{array}{l}\text { Parental } \\
\text { hospitalization } \\
\text { for interpersonal } \\
\text { violence or self- } \\
\text { harm }\end{array}$ & $\begin{array}{l}\text { ICD9: E950-E959; E960-E969; E970-E979 } \\
\text { ICD10: X85-Y09; Y871; X60-X84; Y870; Y10- } \\
\text { Y34; Y872 }\end{array}$ & Child's age $0-12$ & $\begin{array}{l}\text { Hospital discharge } \\
\text { records (1987-2011), } \\
\text { National Institute for } \\
\text { Health and Welfare }\end{array}$ \\
\hline $\begin{array}{l}\text { Parental } \\
\text { criminality }\end{array}$ & $\begin{array}{l}\text { Violent, sexual or property offences known to } \\
\text { police }\end{array}$ & $\begin{array}{l}\text { Child's age: } \\
\text { Cohort 1986:10-12 } \\
\text { Cohort 1987: 9-12 } \\
\text { ‥ } \\
\text { Cohort 1998: 0-12 }\end{array}$ & $\begin{array}{l}\text { Offences known to } \\
\text { police (1996-2012), } \\
\text { Statistics Finland }\end{array}$ \\
\hline $\begin{array}{l}\text { Parental } \\
\text { education }\end{array}$ & Basic, Secondary, Tertiary & Child's age $0-12$ & $\begin{array}{l}\text { Statistics Finland } \\
(1987-2012)\end{array}$ \\
\hline $\begin{array}{l}\text { Childhood } \\
\text { income }\end{array}$ & $\begin{array}{l}\text { Mean household income subject to state taxation } \\
\text { (adjusted for inflation, divided by consumption } \\
\text { units) during childhood, divided into quartiles. }\end{array}$ & Child's age $0-12$ & $\begin{array}{l}\text { Statistics Finland } \\
(1987-2012)\end{array}$ \\
\hline $\begin{array}{l}\text { Region of } \\
\text { residence }\end{array}$ & $\begin{array}{l}\text { Catchment areas of highly specialized medical } \\
\text { care defined by University Central Hospitals of } \\
\text { Helsinki, Tampere, Kuopio, Turku and Oulu }\end{array}$ & $\begin{array}{l}\text { At the end of the } \\
\text { preceding year, } \\
\text { updated during } \\
\text { follow-up }\end{array}$ & $\begin{array}{l}\text { Statistics Finland } \\
(1987-2012)\end{array}$ \\
\hline
\end{tabular}




\section{Empirical approach}

Main effects

We use multivariate Cox regression to predict self-harm and follow the individuals from their $13^{\text {th }}$ birthday onwards, until the first date of hospitalization due to self-harm, suicide, death or emigration, or $31^{\text {st }}$ December 2011. Thus, the episodes of self-harm occur between the ages 13 and 25. We constructed two nested models: Model 1 adjusted for region of residence and Model 2 further adjusted for parental education and childhood income and we estimated separate models for all the parental adversities. Offspring gender violated the proportional hazards assumption in these models: self-harm had an earlier onset and was more common among girls. Therefore, the main effect models are estimated separately for boys and girls. To account for the correlation between siblings, we cluster standard errors by parent's identification number. Interaction analyses and accumulation of adversity

In order to test for interaction effects of offspring gender, we perform multiplicative and additive interaction analyses. We study multiplicative interaction by adding an adversity measure, offspring gender and interaction term into a Cox model adjusted for region of residence. Second, we assess additive interaction effects by calculating relative excess risks due to interaction (RERI), which is "the increased hazard due to additive interaction as a proportion of the hazard given both risk factors at 0 levels" [32]. RERI equals 0 if there is no interaction on an additive scale [32,33]. The estimate informs the direction of interaction but not the magnitude [33] and therefore we also calculate rates of self-harm for sub-groups.

To assess the possible moderating effects between parents, we test for interaction between any maternal and any paternal adversity, following the procedure presented above, with the exception of stratifying the model by offspring gender, thus adjusting for offspring gender effects by allowing a different baseline hazard for boys and girls. Lastly, we test similarly for interaction effects between 
childhood low-income, defined as lowest quartile of mean income during childhood, and parental adversities.

Previous work on childhood adversities has often used sum variables as measures of cumulative disadvantage $[9,10,13]$. We use a similar approach and combine all maternal adversities into one variable consisting of four classes $(0,1,2,3$ or more) and all paternal adversities into another. The two different measures of psychiatric disorders and substance abuse are counted only once (either/or/both). In addition, we construct a variable with five categories combining both parents, with an upper limit of four or more adversities. The modelling strategy follows the approach used with the main effect models.

\section{RESULTS}

\section{Main effects}

In total, there occurred 685 events of self-harm (girls 61\%) during the follow-up, of which 602 hospitalizations (girls 66\%) and 83 suicides (girls 23\%). The rates of self-harm (per 100,000 person-years) ranged between 33.1 at the age of 14 and 125.8 at the age of 20 (unadjusted survival curves are shown in Supplementary Figures 3-6). The most common method of self-harm among hospitalizations was self-poisoning (88\%). Among suicides, the most frequently used methods were hanging, suffocation or strangulation (35\%) and firearms (22\%). The mean age of self-harm was 18.2 years among girls and 19.5 among boys.

The distributions of parental adversities and the results from the main effect analyses are presented in Table 2. The distributions were similar among boys and girls. Paternal adversity was more common than maternal, especially criminality and substance abuse, whereas maternal purchases of psychotropic medication were more prevalent than paternal purchases. Paternal and maternal adversities were not very highly correlated. 
The associations in Model 1 were all statistically significant, with hazard ratios ranging from 1.5 (95\% CI: $1.1,2.0)$ to 5.4 (95\% CI: 2.9,10.1) among boys and from 1.7 (95 CI: 1.4,2.2) to 3.9

(95\%CI: 2.2, 6.7) among girls (Table 2). Overall, the hazard ratios were higher among boys than among girls. In addition, the associations seemed stronger for maternal than paternal adversities across offspring gender. After adjusting for parental education and childhood income in Model 2, all the associations remained statistically significant (Table 2, distributions of control variables are shown in Supplementary Table 1). For both boys and girls, the lowest hazard ratios were for paternal and maternal purchases of psychotropic medication and highest for maternal hospitalization for interpersonal violence.

Table 2: Prevalence of parental adversities, Hazard Ratios (HR) and 95\% Confidence Intervals (95\% CI) of self-harm

BOYS (520,141 person-years)

Maternal characteristics

Substance abuse (hosp.)

Substance abuse (crim.)

Psychiatric disorder (hosp.)

Psychiatric disorder (med.)

Interpersonal violence or self-harm

Criminality

Paternal characteristics

Substance abuse (hosp.)

Substance abuse (crim.)

Psychiatric disorder (hosp.)

Psychiatric disorder (med.)

Interpersonal violence or self-harm

Criminality

GIRLS (496,006 person-years)

Maternal characteristics

Substance abuse (hosp.)

Substance abuse (crim.)

Psychiatric disorder (hosp.)

Psychiatric disorder (med.)

Interpersonal violence or self-harm

Criminality

Paternal characteristics

Substance abuse (hosp.)

Substance abuse (crim.)

Psychiatric disorder (hosp.)

\begin{tabular}{cccccccc} 
& & \multicolumn{3}{c}{ Model 1 } & \multicolumn{3}{c}{ Model 2 } \\
Person-years & $\%$ & HR & $95 \%$ CI & HR & $95 \%$ CI \\
7,387 & 1.4 & 4.15 & 2.48 & 6.94 & 3.21 & 1.91 & 5.37 \\
4,442 & 0.9 & 5.38 & 2.88 & 10.07 & 4.02 & 2.14 & 7.55 \\
14,471 & 2.8 & 2.58 & 1.61 & 4.15 & 2.19 & 1.35 & 3.54 \\
116,215 & 22.3 & 1.72 & 1.32 & 2.22 & 1.62 & 1.25 & 2.11 \\
4,891 & 0.9 & 5.18 & 3.00 & 8.96 & 4.06 & 2.36 & 6.97 \\
11,871 & 2.3 & 2.91 & 1.70 & 4.98 & 2.12 & 1.23 & 3.65 \\
& & & & & & & \\
18,038 & 3.5 & 3.84 & 2.67 & 5.53 & 3.18 & 2.21 & 4.59 \\
26,802 & 5.2 & 2.25 & 1.50 & 3.38 & 1.83 & 1.22 & 2.76 \\
15,711 & 3.0 & 2.33 & 1.44 & 3.77 & 2.00 & 1.23 & 3.22 \\
86,393 & 16.6 & 1.50 & 1.12 & 2.01 & 1.41 & 1.06 & 1.89 \\
7,166 & 1.4 & 2.80 & 1.49 & 5.25 & 2.26 & 1.20 & 4.26 \\
41,009 & 7.9 & 1.93 & 1.34 & 2.78 & 1.59 & 1.10 & 2.30
\end{tabular}

\begin{tabular}{cccccccc} 
Person-years & $\%$ & HR & \multicolumn{2}{c}{$95 \%$ CI } & HR & \multicolumn{2}{c}{$95 \%$ CI } \\
6,778 & 1.4 & 2.72 & 1.62 & 4.56 & 2.16 & 1.29 & 3.61 \\
4,200 & 0.8 & 3.09 & 1.65 & 5.80 & 2.43 & 1.30 & 4.55 \\
13,749 & 2.8 & 3.08 & 2.16 & 4.40 & 2.63 & 1.84 & 3.77 \\
111,518 & 22.5 & 1.76 & 1.44 & 2.16 & 1.69 & 1.38 & 2.08 \\
4,132 & 0.8 & 3.85 & 2.22 & 6.70 & 3.11 & 1.79 & 5.39 \\
11,490 & 2.3 & 2.65 & 1.71 & 4.11 & 2.08 & 1.34 & 3.22 \\
& & & & & & & \\
17,285 & 3.5 & 2.38 & 1.67 & 3.40 & 1.97 & 1.37 & 2.82 \\
25,234 & 5.1 & 1.97 & 1.41 & 2.75 & 1.63 & 1.16 & 2.29 \\
15,140 & 3.1 & 2.48 & 1.71 & 3.60 & 2.10 & 1.44 & 3.06
\end{tabular}




$\begin{array}{lcccccccc}\text { Psychiatric disorder (med.) } & 84,510 & 17.0 & 1.72 & 1.38 & 2.15 & 1.63 & 1.31 & 2.04 \\ \text { Interpersonal violence or self-harm } & 7,350 & 1.5 & 2.68 & 1.63 & 4.41 & 2.19 & 1.32 & 3.62 \\ \text { Criminality } & 39,813 & 8.0 & 2.26 & 1.74 & 2.95 & 1.91 & 1.46 & 2.51\end{array}$

Model 1: Adjusted for region of residence

Model 2: Model $1+$ maternal or paternal education + childhood mean income quartiles

All separate models

\section{Interaction analyses and accumulation of adversity}

We did not find statistically significant multiplicative interactions between parental adversity and offspring gender. However, several of the RERIs calculated were statistically significant, indicating that experiencing adversity may be more harmful for girls than it is for boys. The interaction effect between childhood adversity and offspring gender shows also in Figure 1. Experiencing paternal adversity increased the rate of self-harm by $58 \%$ and maternal by $57 \%$ among girls, whereas for boys, maternal adversity increased the rate of self-harm by $44 \%$ and paternal $35 \%$.

In a similar vein, there was a statistically significant interaction on the additive scale between any maternal and any paternal adversity (results not shown), which suggests that children experiencing both maternal and paternal adversities are likely to be at a higher risk of self-harm than those exposed to adversities of only one parent. This observation is supported by the rates of self-harm (Figure 1), which indicate that the joint effect of parents is more than additive. Adversity of both parents nearly tripled the rate of self-harm among girls and increased the rate 2.5 -fold among boys.

Furthermore, we found several statistically significant additive interactions between economic disadvantage and parental adversities (Supplementary Tables 2 and 3), suggesting that among children in low-income households, parental adversities might increase the risk of self-harm more than in higher-income households. In addition, a similar interaction effect was found on multiplicative scale between paternal purchases of prescription medication and economic disadvantage. Rates of self-harm for the joint-effect of experiencing any adversity and economic disadvantage confirm these findings (Figure 2). The experience of both parental adversity and 
economic disadvantage more than tripled the rate of self-harm among girls and increased the rate among boys 2.7 times, which is a clear interaction effect.

Lastly, our results from the accumulation analysis suggest that exposure to multiple adversities has a cumulative effect on self-harm: the more adversities the higher the risk of self-harm (Table 3).

The same applies for both maternal and paternal characteristics. When both parents were combined, a similar gradient was found.

Table 3: The associations between accumulation of adversities and self-harm. Distributions of accumulation, Hazard Ratios (HR) and 95\% Confidence Intervals (95\% CI).

\begin{tabular}{|c|c|c|c|c|c|c|c|c|}
\hline \multicolumn{3}{|l|}{ BOYS $(520,141$ person-years $)$} & \multicolumn{3}{|c|}{ Model 1} & \multicolumn{3}{|c|}{ Model 2} \\
\hline Number of adversities & Person-years & $\%$ & HR & \multicolumn{2}{|c|}{$95 \% \mathrm{CI}$} & HR & \multicolumn{2}{|c|}{$95 \% \mathrm{CI}$} \\
\hline Maternal (ref. 0) & 391,782 & 75.3 & 1.00 & & & 1.00 & & \\
\hline 1 & 115,705 & 22.2 & 1.60 & 1.22 & 2.10 & 1.52 & 1.16 & 2.00 \\
\hline 2 & 8,354 & 1.6 & 2.82 & 1.45 & 5.52 & 2.18 & 1.12 & 4.24 \\
\hline 3 or 4 & 4,301 & 0.8 & 7.73 & 4.44 & 13.47 & 5.76 & 3.30 & 10.07 \\
\hline Paternal (ref. 0) & 389,202 & 74.8 & 1.00 & & & 1.00 & & \\
\hline 1 & 97,822 & 18.8 & 1.50 & 1.12 & 2.00 & 1.40 & 1.05 & 1.88 \\
\hline 2 & 22,866 & 4.4 & 1.66 & 0.98 & 2.81 & 1.39 & 0.82 & 2.35 \\
\hline 3 or 4 & 10,251 & 2.0 & 4.92 & 3.05 & 7.92 & 3.85 & 2.36 & 6.26 \\
\hline Combined (ref. 0) & 306,601 & 58.9 & 1.00 & & & 1.00 & & \\
\hline 1 & 143,277 & 27.5 & 1.43 & 1.08 & 1.90 & 1.37 & 1.03 & 1.82 \\
\hline 2 & 44,981 & 8.6 & 1.89 & 1.26 & 2.81 & 1.67 & 1.12 & 2.49 \\
\hline 3 & 17,404 & 3.3 & 2.30 & 1.30 & 4.09 & 1.89 & 1.06 & 3.37 \\
\hline 4 or more & 7,878 & 1.5 & 7.35 & 4.68 & 11.55 & 5.27 & 3.30 & 8.42 \\
\hline \multicolumn{9}{|l|}{ GIRLS (496,006 person-years) } \\
\hline Number of adversities & Person-years & $\%$ & HR & \multicolumn{2}{|c|}{$95 \% \mathrm{CI}$} & HR & \multicolumn{2}{|c|}{$95 \% \mathrm{CI}$} \\
\hline Maternal (ref. 0) & 373,657 & 75.3 & 1.00 & & & 1.00 & & \\
\hline 1 & 110,335 & 22.2 & 1.75 & 1.42 & 2.16 & 1.69 & 1.37 & 2.09 \\
\hline 2 & 8,039 & 1.6 & 3.44 & 2.13 & 5.54 & 2.76 & 1.71 & 4.48 \\
\hline 3 or 4 & 3,975 & 0.8 & 3.40 & 1.75 & 6.60 & 2.69 & 1.39 & 5.21 \\
\hline Paternal (ref. 0) & 369,427 & 74.5 & 1.00 & & & 1.00 & & \\
\hline 1 & 94,098 & 19.0 & 1.59 & 1.26 & 2.01 & 1.51 & 1.20 & 1.90 \\
\hline 2 & 22,378 & 4.5 & 2.60 & 1.84 & 3.65 & 2.21 & 1.57 & 3.13 \\
\hline 3 or 4 & 10,103 & 2.0 & 3.52 & 2.30 & 5.39 & 2.86 & 1.85 & 4.43 \\
\hline Combined (ref. 0) & 290,849 & 58.6 & 1.00 & & & 1.00 & & \\
\hline 1 & 137,236 & 27.7 & 1.44 & 1.14 & 1.82 & 1.41 & 1.11 & 1.77 \\
\hline 2 & 43,644 & 8.8 & 2.65 & 2.00 & 3.51 & 2.42 & 1.82 & 3.21 \\
\hline 3 & 16,748 & 3.4 & 2.95 & 1.95 & 4.45 & 2.53 & 1.67 & 3.83 \\
\hline 4 or more & 7,529 & 1.5 & 5.22 & 3.45 & 7.88 & 4.24 & 2.78 & 6.46 \\
\hline
\end{tabular}

Model 1: Adjusted for region of residence

Model 2: Model $1+$ maternal or paternal education + childhood mean income quartiles

Maternal, paternal and combined from separate models 


\section{DISCUSSION}

\section{Main findings}

To our knowledge, this is the first study to show explicitly that both paternal and maternal adversities increase the risk of self-harm. We also documented for the first time that the effects of these adversities on later self-harm are more pertinent for children coming from low-income families. However, we did not find evidence that the association between parental adversities and self-harm would depend on parent gender. The only major gender difference in parental adversities was in prevalence: fathers were more likely to have experienced adversities related to substance and alcohol abuse and criminality, as well as multiple adversities and mothers more likely to have used psychotropic medication. Thus, when assessing childhood adversities with combined parental information $[9,10]$, fathers are likely to contribute more to the total amount of adversities. This is especially true if the less severe adversities, such as psychotropic medication use in this study, are not assessed.

In keeping with previous knowledge on gender differences in self-harm [1,2,4,34], girls accounted for a larger share of hospitalizations and the behavior had an earlier onset. These differences in selfharm might be explained by the higher prevalence of mental health problems among girls and earlier onset of puberty [35]. Males were overrepresented among suicides, which is likely to be related to the choice of method and higher rates of aggressive behavior and substance abuse among males [36]. Our results also imply that experiencing adversity might be more harmful for girls. It has been argued that experience of childhood adversity might increase depression more among girls than boys [37], and depression is known to increase the risk of subsequent self-harm [22]. However, these gender differences in the pathways from childhood adversities to self-harm in adolescence and young adulthood require further investigation.

We found clear evidence that maternal and paternal adversities are more detrimental in low-income households. In previous literature, economic disadvantage has often been assessed as an 
independent dimension of childhood adversity but, to the best of our knowledge, interaction analyses by childhood economic disadvantage in the association between parental adversities and self-harm have not been conducted. The more severe effects of these adversities may reflect greater vulnerability in low-income households [19]. Parental adversities are known to be more common in low-income families [19-21] and they can also be more long-lasting and of greater intensity in the lower income groups. Furthermore, to cope with both material daily necessities and adversities with limited economic resources is likely to be highly stressful for both parents and their children.

In addition, we showed that the effects of childhood adversities are cumulative: the more adversities, the higher the risk of hospitalization for self-harm and that the gradient applies to both parents. The former replicates previous findings $[9,10]$ but the latter association has not been previously shown. Furthermore, our results indicate that parental adversities reinforce each other, possibly because of the increased exposure to inadequate parental support and protection concerning both parents [38].

As we measured the parental adversities of biological parents regardless of the living arrangements and co-residence with children, we ran a sensitivity analysis to test the effect of the extent of exposure to adversities by limiting the analyses to children who have lived with their biological parents for their whole childhood (0-12-years). There were considerably fewer adversities in the limited study population, suggesting that children who do not reside their childhood in intact families are an especially high-risk group. Nevertheless, the associations between adversity and self-harm were largely similar among the limited study population (Supplementary Table 4) but adjusting for parental education and childhood income attenuated the hazards ratios very little, which indicates that the intact families are a more selected group in terms of parental education and income. We also ran a sensitivity analysis in which we only evaluate those adversities that occurred while the children resided with the parent in question and the results from this analysis and our main models were similar (Supplementary Table 5). 
The fact that different adversities, family stability and socioeconomic conditions are closely correlated might lead to an underestimation of the importance of socioeconomic resources in analyses where all these dimensions of childhood are lumped together [39]. Our results suggest that children in low-income families seem to be at an elevated risk of self-harm when not exposed to adversities and more when exposed. Therefore, improving socioeconomic circumstances might be a good place to start with public health interventions [39]. However, our sensitivity analysis suggests that in intact families, where socioeconomic resources have a smaller role, parental adversities are still hazardous. This implies that targeted interventions for children exposed to adversities are needed [39].

\section{Strengths and limitations}

The use of administrative data enables to study a large sample of adolescents and young adults without recall bias or attrition. The data contains annually updated information on diverse childhood exposures and clinically defined outcome and therefore the measures of childhood adversities, selfharm and suicides are reliable. However, we were not able to determine the degree of suicidal intent in the episodes of self-harm. It is likely that the non-lethal self-harm episodes in this study have been quite severe, as hospital care has been required. In a Swedish register-based study [9], which was able to use additional information from other health and care service records, self-harm was much more common. Nevertheless, the results of these two studies on the association between childhood adversity and self-harm are similar, thus building the credibility of our results.

Our measures of adversities and self-harm, even though reliable, do underestimate the total prevalence in the community. Especially for substance abuse and parental violent victimization, we capture only the most severe forms. Therefore, it is not surprising that we see strong associations between extreme adversities and extreme outcome. However, we included measures of psychotropic medication purchases and found that these less severe parental mental health problems 
increase the risk of self-harm by about $50-70 \%$, which indicates that the more common adversities are also harmful for children.

According to our results, only a small proportion of those with experiences of parental adversities end up harming themselves and many with no adverse experience captured by our measures do. The latter is partly related to our underestimation of the prevalence of parental adversities. Nevertheless, it is clear that there are other pertinent personal $[9,23,35]$ and interpersonal $[40]$ determinants of every self-harm episode in adolescence and young adulthood. However, these factors, more related to adolescents themselves than their parents, are likely to evolve in an interplay with childhood adversities. Our findings demonstrating how maternal and paternal adversities and their interaction with family income contribute to increased risk of self-harm are important factors to consider when planning effective policy measures and interventions. 


\section{Acknowledgments}

The authors wish to thank Statistics Finland for granting access to the data.

\section{Contributions}

JP participated in the conception and design of the study, performed statistical analyses and wrote the first version of the manuscript. HR, MA and PM participated in the conception and design of the study, and read and revised the draft versions of the manuscript. All authors contributed to all sections of manuscript and approved the final version.

\section{Funding}

This study was supported by Academy of Finland [grant numbers 308247 and 316595 ].

\section{Competing Interest}

All the authors reported grants from Academy of Finland, during the conduct of the study.

\section{Ethics Approval}

The study has been approved by Statistics Finland Board of Statistical Ethics (TK-53-525-11).

\section{Licence for Publication}

The Corresponding Author has the right to grant on behalf of all authors and does grant on behalf of all authors, an exclusive licence (or non exclusive for government employees) on a worldwide basis to the BMJ Publishing Group Ltd to permit this article (if accepted) to be published in JECH and any other BMJPGL products and sublicences such use and exploit all subsidiary rights, as set out in our licence (http://group.bmj.com/products/journals/instructions-for-authors/licence-forms). 


\section{REFERENCES}

1 Hawton K, Saunders KE, O'Connor RC. Self-harm and suicide in adolescents. The Lancet 2012;379:2373-82. doi:10.1016/S0140-6736(12)60322-5

2 Geulayov G, Casey D, McDonald KC, et al. Incidence of suicide, hospital-presenting non-fatal self-harm, and community-occurring non-fatal self-harm in adolescents in England (the iceberg model of self-harm): a retrospective study. The Lancet Psychiatry 2018;5:167-74. doi:10.1016/S2215-0366(17)30478-9

3 Hamza CA, Stewart SL, Willoughby T. Examining the link between nonsuicidal self-injury and suicidal behavior: a review of the literature and an integrated model. Clin Psychol Rev 2012;32:482-95. doi:10.1016/j.cpr.2012.05.003

4 Evans E, Hawton K, Rodham K, et al. The prevalence of suicidal phenomena in adolescents: A systematic review of population-based studies. Suicide Life-Threat Behav 2005;35:239-50. doi:10.1521/suli.2005.35.3.239

5 Gillies D, Christou MA, Dixon AC, et al. Prevalence and Characteristics of Self-Harm in Adolescents: Meta-Analyses of Community-Based Studies 1990-2015. Journal of the American Academy of Child \& Adolescent Psychiatry 2018;57:733-41. doi:10.1016/j.jaac.2018.06.018

6 Eurostat. 3. Health. In: Being young in Europe today. Luxembourg: : Eurostat 2017. https://ec.europa.eu/eurostat/statistics-explained/index.php/Being_young_in_Europe_today (accessed 8 Apr 2019).

7 Evans E, Hawton K, Rodham K. Factors associated with suicidal phenomena in adolescents: A systematic review of population-based studies. Clinical Psychology Review 2004;24:957-79. doi:10.1016/j.cpr.2004.04.005

8 Arbuthnott AE, Lewis SP. Parents of youth who self-injure: a review of the literature and implications for mental health professionals. Child and Adolescent Psychiatry and Mental Health 2015;9:35. doi:10.1186/s13034-015-0066-3

9 Björkenstam E, Kosidou K, Björkenstam C. Childhood household dysfunction and risk of selfharm: a cohort study of 107518 young adults in Stockholm County. Int J Epidemiol 2016;45:501-11. doi:10.1093/ije/dyw012

10 Dube SR, Anda RF, Felitti VJ, et al. Childhood Abuse, Household Dysfunction, and the Risk of Attempted Suicide Throughout the Life Span: Findings From the Adverse Childhood Experiences Study. JAMA 2001;286:3089-96. doi:10.1001/jama.286.24.3089

11 Serafini G, Muzio C, Piccinini G, et al. Life adversities and suicidal behavior in young individuals: a systematic review. Eur Child Adolesc Psychiatry 2015;24:1423-46. doi:10.1007/s00787-015-0760-y

12 Björkenstam E, Björkenstam C. Childhood adversity and risk of suicide: cohort study of 548721 adolescents and young adults in Sweden. BMJ 2017;357:j1334. doi:10.1136/bmj.j1334 
13 Björkenstam E, Hjern A, Björkenstam C, et al. Association of Cumulative Childhood Adversity and Adolescent Violent Offending With Suicide in Early Adulthood. JAMA Psychiatry 2018;75:185-93. doi:10.1001/jamapsychiatry.2017.3788

14 Agerbo E, Nordentoft M, Mortensen PB. Familial, psychiatric, and socioeconomic risk factors for suicide in young people: Nested case-control study. British Medical Journal: BMJ, International edition; London 2002;325:74.

15 Jablonska B. A national cohort study of parental socioeconomic status and non-fatal suicidal behaviour-the mediating role of school performance. BMC Public Health 2012;12:17.

16 Page A, Lewis G, Kidger J, et al. Parental socio-economic position during childhood as a determinant of self-harm in adolescence. Soc Psychiatry Psychiatr Epidemiol 2014;49:193-203. doi:10.1007/s00127-013-0722-y

17 Remes H, Martikainen P. Young adult's own and parental social characteristics predict injury morbidity: a register-based follow-up of 135000 men and women. BMC Public Health 2015;15:429. doi:10.1186/s12889-015-1763-9

18 Beautrais AL. Risk Factors for Suicide and Attempted Suicide among Young People. Aust N Z J Psychiatry 2000;34:420-36. doi:10.1080/j.1440-1614.2000.00691.x

19 Mok PLH, Antonsen S, Pedersen CB, et al. Family income inequalities and trajectories through childhood and self-harm and violence in young adults: a population-based, nested case-control study. The Lancet Public Health 2018;3:e498-507. doi:10.1016/S2468-2667(18)30164-6

20 Remes H, Moustgaard H, Kestilä LM, et al. Parental education and adolescent health problems due to violence, self-harm and substance use: what is the role of parental health problems? $J$ Epidemiol Community Health 2019;73:225-31. doi:10.1136/jech-2018-211316

21 Paranjothy S, Evans A, Bandyopadhyay A, et al. Risk of emergency hospital admission in children associated with mental disorders and alcohol misuse in the household: an electronic birth cohort study. The Lancet Public Health 2018;3:e279-88. doi:10.1016/S24682667(18)30069-0

22 Miranda-Mendizabal A, Castellví P, Parés-Badell O, et al. Gender differences in suicidal behavior in adolescents and young adults: systematic review and meta-analysis of longitudinal studies. Int J Public Health Published Online First: 12 January 2019. doi:10.1007/s00038-0181196-1

23 Perez NM, Jennings WG, Piquero AR, et al. Adverse Childhood Experiences and Suicide Attempts: The Mediating Influence of Personality Development and Problem Behaviors. $J$ Youth Adolesc 2016;45:1527-45. doi:10.1007/s10964-016-0519-x

24 Felitti VJ, Anda RF, Nordenberg D, et al. Relationship of Childhood Abuse and Household Dysfunction to Many of the Leading Causes of Death in Adults: The Adverse Childhood Experiences (ACE) Study. American Journal of Preventive Medicine 1998;14:245-58. doi:10.1016/S0749-3797(98)00017-8

25 De Bellis MD, Broussard ER, Herring DJ, et al. Psychiatric co-morbidity in caregivers and children involved in maltreatment: a pilot research study with policy implications. Child Abuse Negl 2001;25:923-44. 
26 Mikkonen J, Moustgaard H, Remes H, et al. Intergenerational transmission of depressive symptoms - The role of gender, socioeconomic circumstances, and the accumulation of parental symptoms. Journal of Affective Disorders 2016;204:74-82. doi:10.1016/j.jad.2016.06.036

27 Aunola K, Nurmi J-E. The Role of Parenting Styles in Children's Problem Behavior. Child Development 2005;76:1144-59. doi:10.1111/j.1467-8624.2005.00840.x-i1

28 Elgar FJ, Mills RSL, McGrath PJ, et al. Maternal and Paternal Depressive Symptoms and Child Maladjustment: The Mediating Role of Parental Behavior. J Abnorm Child Psychol 2007;35:943-55. doi:10.1007/s10802-007-9145-0

29 Milevsky A, Schlechter M, Netter S, et al. Maternal and Paternal Parenting Styles in Adolescents: Associations with Self-Esteem, Depression and Life-Satisfaction. J Child Fam Stud 2007;16:39-47. doi:10.1007/s10826-006-9066-5

30 Russell A, Saebel J. Mother-Son, Mother-Daughter, Father-Son, and Father-Daughter: Are They Distinct Relationships? Developmental Review 1997;17:111-47. doi:10.1006/drev.1996.0431

31 Rosenthal NL, Kobak R. Assessing Adolescents' Attachment Hierarchies: Differences Across Developmental Periods and Associations With Individual Adaptation. J Res Adolesc 2010;20:678-706. doi:10.1111/j.1532-7795.2010.00655.x

$32 \mathrm{Li} \mathrm{R}$, Chambless L. Test for additive interaction in proportional hazards models. Ann Epidemiol 2007;17:227-36. doi:10.1016/j.annepidem.2006.10.009

33 VanderWeele TJ, Knol MJ. A Tutorial on Interaction. Epidemiologic Methods 2014;3. doi:10.1515/em-2013-0005

34 Hawton K. Sex and suicide: Gender differences in suicidal behaviour. The British Journal of Psychiatry 2000;177:484-5. doi:10.1192/bjp.177.6.484

35 Kaess M, Parzer P, Haffner J, et al. Explaining gender differences in non-fatal suicidal behaviour among adolescents: a population-based study. BMC Public Health 2011;11:597. doi:10.1186/1471-2458-11-597

36 Spirito A, Esposito-Smythers C. Attempted and Completed Suicide in Adolescence. Annu Rev Clin Psychol 2006;2:237-66. doi:10.1146/annurev.clinpsy.2.022305.095323

37 Zahn-Waxler C, Shirtcliff EA, Marceau K. Disorders of Childhood and Adolescence: Gender and Psychopathology. Annu Rev Clin Psychol 2008;4:275-303. doi:10.1146/annurev.clinpsy.3.022806.091358

38 Brennan PA, Hammen C, Katz AR, et al. Maternal depression, paternal psychopathology, and adolescent diagnostic outcomes. Journal of Consulting and Clinical Psychology 2002;70:107585. doi:10.1037/0022-006X.70.5.1075

39 Taylor-Robinson DC, Straatmann VS, Whitehead M. Adverse childhood experiences or adverse childhood socioeconomic conditions? The Lancet Public Health 2018;3:e262-3. doi:10.1016/S2468-2667(18)30094-X 
40 Johnson JG, Cohen P, Gould MS, et al. Childhood Adversities, Interpersonal Difficulties, and Risk for Suicide Attempts During Late Adolescence and Early Adulthood. Arch Gen Psychiatry 2002;59:741-9. doi:10.1001/archpsyc.59.8.741 


\section{FIGURES}

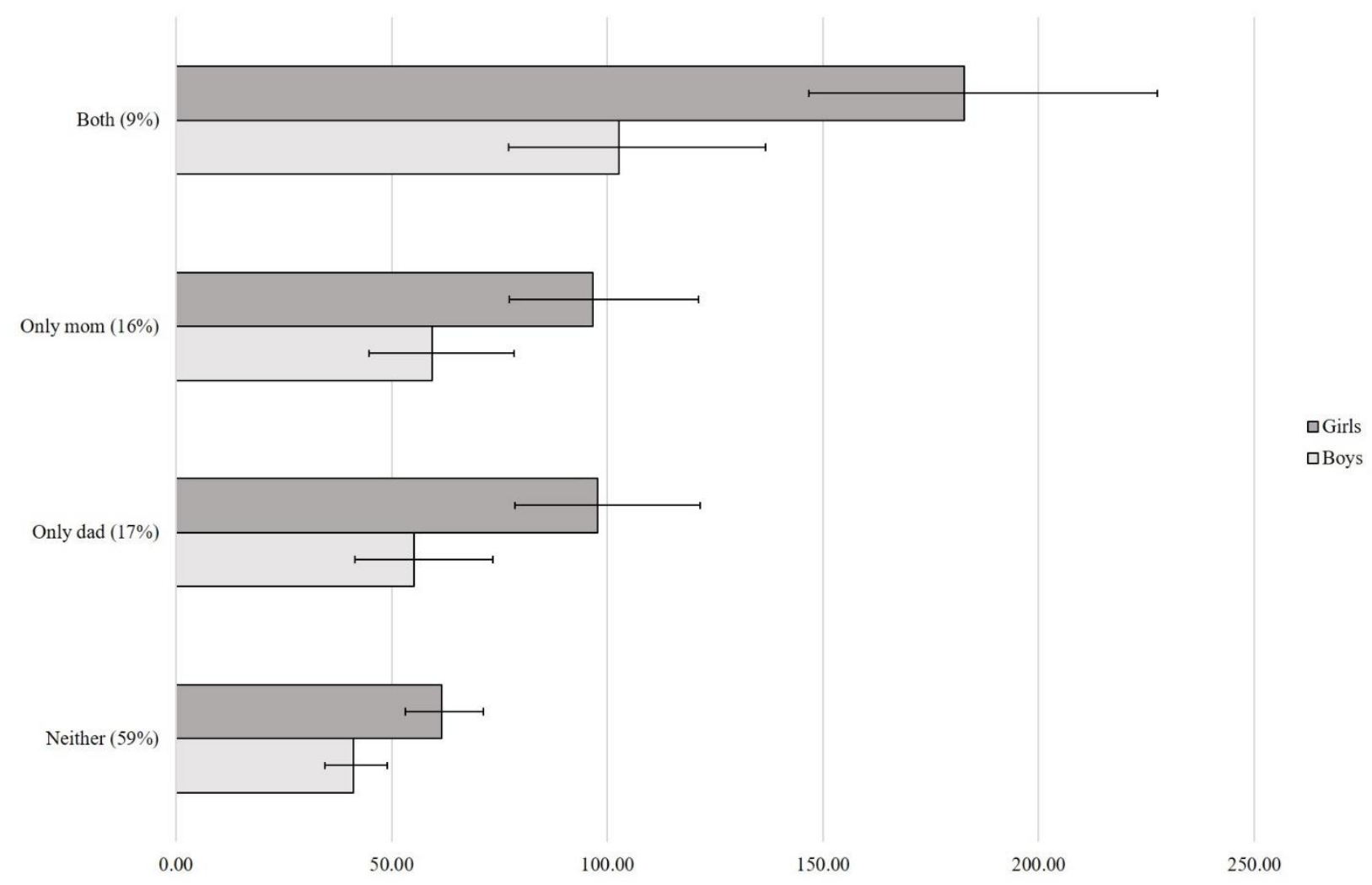

Figure 1: Rates (per 100,000 person-years) of self-harm by parental adversity. Distribution of combinations in brackets. 


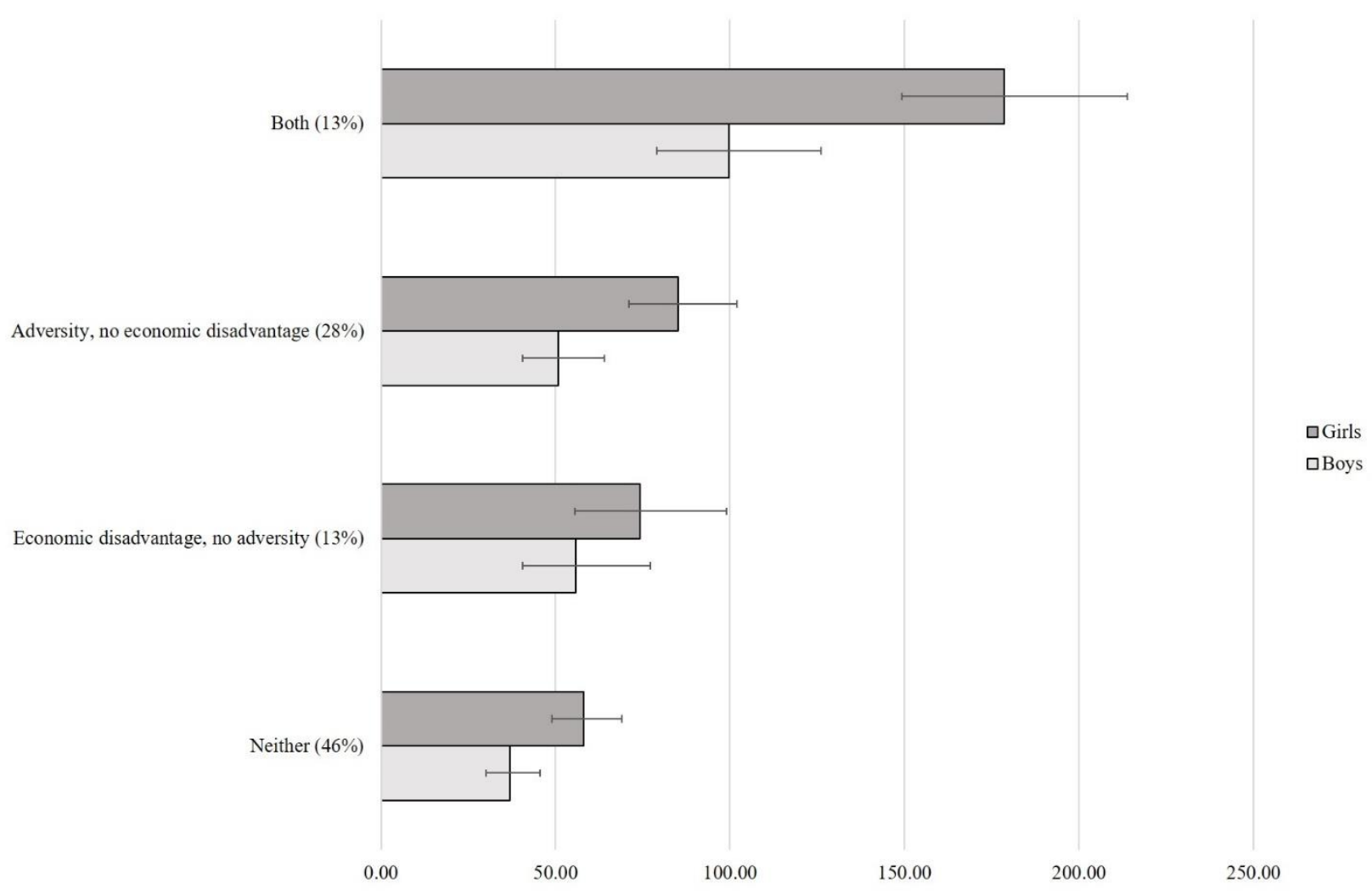

Figure 2: Rates (per 100,000 person-years) of self-harm by childhood adversity and childhood economic disadvantage. Distribution of combinations in brackets. 